TAIWANESE JOURNAL OF MATHEMATICS

Vol. 9, No. 1, pp. 81-94, March 2005

This paper is available online at http://www.math.nthu.edu.tw/tjm/

\title{
A CLASS OF THIRD ORDER MULTI-POINT BOUNDARY VALUE PROBLEM
}

\author{
Zengji Du, Guolan Cai and Weigao Ge
}

\begin{abstract}
This paper deals with a class of third order multi-point boundary value problem at resonance case. Some existence theorems are obtained by using the coincidence degree theory of Mawhin.
\end{abstract}

\section{INTRODUCTION}

In this paper, we are concerned with the following third order ordinary differential equation:

$$
x^{\prime \prime \prime}(t)=f\left(t, x(t), x^{\prime}(t), x^{\prime \prime}(t)\right), \quad t \in(0,1),
$$

with the following multi-point boundary conditions:

$$
x(0)=\alpha x(\xi), x^{\prime \prime}(0)=0, \quad x^{\prime}(1)=\sum_{j=1}^{m-2} \beta_{j} x^{\prime}\left(\eta_{j}\right) .
$$

Where $f:[0,1] \times R^{3} \longrightarrow R$ is a continuous function, $\alpha \geq 0, \beta_{j}(j=1, \cdots, m-2$, $\in R, 0<\xi<1,0<\eta_{1}<\eta_{2}<\cdots<\eta_{m-2}<1$, all $\beta_{i}^{\prime} s$ have the same sign.

Similar to $[1,2]$, if the linear equation $x^{\prime \prime \prime}(t)=0$, with boundary conditions (1.2) has only zero solution, and the differential operator defined in a suitable Banach space, with boundary conditions taken into account, is invertible, the socalled non-resonance case; otherwise, is non-invertible, then the so-called resonance case.

Received August 20, 2003; Accepted October 2, 2003.

Communicated by Hal Smith.

2000 Mathematics Subject Classification: 34B10, 34B15.

Key words and phrases: Multi-point boundary value problem, Resonance, Fredholm operator, Coincidence degree theory.

Sponsored by the National Natural Science Foundation and the Doctoral Program Foundation of Education Ministry of China (No. 10371006). 
For the resonance case, it is more delicate. Ma [3] studied existence and multiplity results for the following boundary value problem:

$$
\begin{gathered}
x^{\prime \prime \prime}+k^{2} x^{\prime}+g\left(x, x^{\prime}\right)=p(t), \\
x^{\prime}(0)=x^{\prime}(\pi)=x(\eta)=0,
\end{gathered}
$$

by combining the well-known Lyapunov-Schmidt procedure with the continuum theory for O-epi maps. In the case $k=1$, the solvability of (1.3), (1.4) has been considered by Nagle and Pothoven [4] under the condition that $g$ is bounded on one side. Gupta [5] studied the existence of boundary value problem, similar to (1.3), (1.4) of the type

$$
\begin{gathered}
x^{\prime \prime \prime}+\pi^{2} x^{\prime}+g\left(t, x, x^{\prime}, x^{\prime \prime}\right)=p(t), \\
x^{\prime}(0)=x^{\prime}(1)=x(\eta)=0,0 \leq \eta \leq 1,
\end{gathered}
$$

under some appropriate conditions.

Feng [1], Liu [6] and Gupta [7] studied the existence results for some second order multi-point boundary value problems at resonance case.

Inspired by the work of the above papers, in the present article, we use the coincidence degree theory of Mawhin [8] to discuss the existence of solution for third order multi-point BVP (1.1), (1.2) at resonance case, and establish some existence theorems under sub-linear growth restriction of $f$. For some recent results on third order nonlinear boundary value problems and second order multi-point boundary value problems at resonance case we refer the reader to [9-12].

\section{Main Results}

We first recall some notation and an abstract existence result.

Let $Y, Z$ be real Banach spaces and let $L: \operatorname{dom} L \subset Y \longrightarrow Z$ be a linear operator which is Fredholm map of index zero (that is, $\operatorname{Im} L$, the image of $L, \operatorname{Ker} L$, the kernel of $L$ is finite dimensional with the same dimension as the $Z / \operatorname{Im} L$.) and $P: Y \longrightarrow Y, Q: Z \longrightarrow Z$ be continuous projectors such that $\operatorname{Im} P=$ $\operatorname{Ker} L, \operatorname{Ker} Q=\operatorname{Im} L$ and $Y=\operatorname{Ker} L \oplus \operatorname{Ker} P, Z=\operatorname{Im} L \oplus \operatorname{Im} Q$. It follows that $\left.L\right|_{\operatorname{dom} L \cap \operatorname{Ker} P}: \operatorname{dom} L \cap \operatorname{Ker} P \longrightarrow \operatorname{Im} L$ is invertible, we denote the inverse of that map by $K_{P}$. Let $\Omega$ be an open bounded subset of $Y$ such that $\operatorname{dom} L \cap \Omega$ $\neq \emptyset$, the map $N: Y \longrightarrow Z$ is said to be $L$-compact on $\bar{\Omega}$ if $Q N(\bar{\Omega})$ is bounded and $K_{P}(I-Q) N: \bar{\Omega} \longrightarrow Y$ is compact. Let $J: \operatorname{Im} Q \longrightarrow \operatorname{Ker} L$ be a linear isomorphism.

The theorem we use in the following is the Theorem IV.13 of [8].

Theorem 2.1. Let $L$ be a Fredholm operator of index zero and let $N$ be L-compact on $\bar{\Omega}$. Assume that the following conditions are satisfied: 
(i) $L x \neq \lambda N x$ for every $(x, \lambda) \in[(\operatorname{dom} L \backslash \operatorname{Ker} L) \cap \partial \Omega] \times(0,1)$.

(ii) $N x \notin \operatorname{Im} L$ for every $x \in \operatorname{Ker} L \cap \partial \Omega$.

(iii) $\operatorname{deg}\left(\left.J Q N\right|_{\operatorname{Ker} L}, \Omega \cap \operatorname{Ker} L, 0\right) \neq 0$, where $Q: Z \longrightarrow Z$ is a projection as above with $\operatorname{Im} L=\operatorname{Ker} Q$.

Then the equation $L x=N x$ has at least one solution in $\operatorname{dom} L \cap \bar{\Omega}$.

In the following, we shall use the classical spaces $C[0,1], C^{1}[0,1], C^{2}[0,1]$ and $L^{1}[0,1]$. For $x \in C^{2}[0,1]$, we use the norm $\|x\|_{\infty}=\max _{t \in[0,1]}|x(t)|$ and $\|x\|=$ $\max \left\{\|x\|_{\infty},\left\|x^{\prime}\right\|_{\infty},\left\|x^{\prime \prime}\right\|_{\infty}\right\}$, and denote the norm in $L^{1}[0,1]$ by $\|\cdot\|_{1}$. We will use the Sobolev space $W^{3,1}(0,1)$ which may be defined by

$$
\begin{aligned}
W^{3,1}(0,1)= & \left\{x:[0,1] \longrightarrow R \mid x, x^{\prime}, x^{\prime \prime}\right. \\
& \text { are absolutely continuous on } \left.[0,1] \text { with } x^{\prime \prime \prime} \in L^{1}[0,1]\right\} .
\end{aligned}
$$

Now we prove existence results for BVP (1.1), (1.2) in the following two cases:

(i) $\alpha=0, \sum_{j=1}^{m-2} \beta_{j}=1$;

(ii) $\alpha=1, \sum_{j=1}^{m-2} \beta_{j}=1$.

Let $Y=C^{2}[0,1], Z=L^{1}[0,1], L$ is the linear operator from $\operatorname{dom} L \subset Y$ to $Z$ with

$$
\operatorname{dom} L=\left\{x \in W^{3,1}(0,1): x(0)=\alpha x(\xi), x^{\prime \prime}(0)=0, x^{\prime}(1)=\sum_{j=1}^{m-2} \beta_{j} x^{\prime}\left(\eta_{j}\right)\right\}
$$

and $L x=x^{\prime \prime \prime}, x \in \operatorname{dom} L$. We define $N: Y \longrightarrow Z$ by setting

$$
N x=f\left(t, x(t), x^{\prime}(t), x^{\prime \prime}(t)\right), t \in(0,1) .
$$

Then BVP (1.1), (1.2) can be written as $L x=N x$.

Our first result is the following one dealing with BVP (1.1), (1.2) in case (i).

Theorem 2.2. Let $f:[0,1] \times R^{3} \longrightarrow R$ be a continuous function, assume that

(1) There exist functions $a, b, c, r \in L^{1}[0,1]$, such that for all $(x, y, z) \in R^{3}$, $t \in[0,1]$, satisfying

$$
|f(t, x, y, z)| \leq a(t)|x|+b(t)|y|+c(t)|z|+r(t) .
$$

(2) There exists a constant $M>0$, such that for $x \in \operatorname{dom} L$, if $\left|x^{\prime}(t)\right|>M$, for all $t \in[0,1]$, then

$$
\begin{aligned}
\sum_{j=1}^{m-2} \beta_{j}[ & \int_{0}^{\eta_{j}}\left(1-\eta_{j}\right) f\left(v, x(v), x^{\prime}(v), x^{\prime \prime}(v)\right) d v \\
& \left.+\int_{\eta_{j}}^{1}(1-v) f\left(v, x(v), x^{\prime}(v), x^{\prime \prime}(v)\right) d v\right] \neq 0 .
\end{aligned}
$$


(3) There exists a constant $M^{*}>0$, such that either

$$
c \cdot \sum_{j=1}^{m-2} \beta_{j} \int_{\eta_{j}}^{1} \int_{0}^{\tau} f(v, c v, c, 0) d v d \tau<0, \text { for all }|c|>M^{*},
$$

or else

$$
c \cdot \sum_{j=1}^{m-2} \beta_{j} \int_{\eta_{j}}^{1} \int_{0}^{\tau} f(v, c v, c, 0) d v d \tau>0, \text { for all }|c|>M^{*} .
$$

Then BVP (1.1), (1.2) with $\alpha=0, \sum_{j=1}^{m-2} \beta_{j}=1$, has at least one solution in $C^{2}[0,1]$ if

$$
\|a\|_{1}+\|b\|_{1}+\|c\|_{1}<\frac{1}{2}
$$

We prove this result via the following lemmas.

In the following, we assume that the conditions in Theorem 2.2 are all satisfied.

Lemma 2.1. If $\alpha=0, \sum_{j=1}^{m-2} \beta_{j}=1$, then $L: \operatorname{dom} L \subset Y \longrightarrow Z$ is a Fredholm operator of index zero. Furthermore, the linear continuous projector operator $Q: Z \longrightarrow Z$ can be defined by

$$
Q y=\frac{2}{1-\sum_{j=1}^{m-2} \beta_{j} \eta_{j}^{2}} \sum_{j=1}^{m-2} \beta_{j} \int_{\eta_{j}}^{1} \int_{0}^{\tau} y(v) d v d \tau,
$$

and the linear operator $K_{P}: \operatorname{Im} L \longrightarrow \operatorname{dom} L \cap \operatorname{Ker} P$ can be written by

$$
K_{P} y=\int_{0}^{t} \int_{0}^{s} \int_{0}^{\tau} y(v) d v d \tau d s .
$$

Furthermore

$$
\left\|K_{P}\right\| \leq\|y\|_{1} \text {, for every } y \in \operatorname{Im} L .
$$

Proof. It is clear that

$$
\operatorname{Ker} L=\{x \in \operatorname{dom} L: x=c t, c \in R, t \in[0,1]\} .
$$

Now we show that

$$
\operatorname{Im} L=\left\{y \in Z: \sum_{j=1}^{m-2} \beta_{j} \int_{\eta_{j}}^{1} \int_{0}^{\tau} y(v) d v d \tau=0\right\} .
$$

Since the problem

$$
x^{\prime \prime \prime}=y
$$


has a solution $x(t)$ satisfied $x(0)=\alpha x(\xi), x^{\prime \prime}(0)=0, x^{\prime}(1)=\sum_{j=1}^{m-2} \beta_{j} x^{\prime}\left(\eta_{j}\right)$, if and only if

$$
\sum_{j=1}^{m-2} \beta_{j} \int_{\eta_{j}}^{1} \int_{0}^{\tau} y(v) d v d \tau=0
$$

In fact, if (2.6) has a solution $x(t)$ satisfied $x(0)=\alpha x(\xi), x^{\prime \prime}(0)=0, x^{\prime}(1)=$ $\sum_{j=1}^{m-2} \beta_{j} x^{\prime}\left(\eta_{j}\right)$, then from (2.6) we have

$$
\begin{aligned}
x(t) & =x(0)+x^{\prime}(0) t+\frac{1}{2} x^{\prime \prime}(0) t^{2}+\int_{0}^{t} \int_{0}^{s} \int_{0}^{\tau} y(v) d v d \tau d s \\
& =x^{\prime}(0) t+\int_{0}^{t} \int_{0}^{s} \int_{0}^{\tau} y(v) d v d \tau d s .
\end{aligned}
$$

According to $\sum_{j=1}^{m-2} \beta_{j}=1$, we obtain

$$
\sum_{j=1}^{m-2} \beta_{j} \int_{\eta_{j}}^{1} \int_{0}^{\tau} y(v) d v d \tau=0
$$

On the other hand, if (2.7) holds, setting

$$
x(t)=c t+\int_{0}^{t} \int_{0}^{s} \int_{0}^{\tau} y(v) d v d \tau d s,
$$

where $c$ is an arbitrary constant, then $x(t)$ is a solution of (2.6), and $x(0)=x^{\prime \prime}(0)$ $=0, x^{\prime}(1)=\sum_{j=1}^{m-2} \beta_{j} x^{\prime}\left(\eta_{j}\right)$. Hence (2.5) is valid.

For $y \in Z$, define

$$
Q y(t)=\frac{2}{1-\sum_{j=1}^{m-2} \beta_{j} \eta_{j}^{2}} \sum_{j=1}^{m-2} \beta_{j} \int_{\eta_{j}}^{1} \int_{0}^{\tau} y(v) d v d \tau, 0 \leq t \leq 1 .
$$

Let $y_{1}=y-Q y$, it is easily shown that

$$
\sum_{j=1}^{m-2} \beta_{j} \int_{\eta_{j}}^{1} \int_{0}^{\tau} y_{1}(v) d v d \tau=0
$$

then $y_{1} \in \operatorname{Im} L$. Hence $Z=\operatorname{Im} L+Z_{1}$, where $Z_{1}=\{x(t) \equiv c: t \in[0,1], c \in R\}$, also $\operatorname{Im} L \cap Z_{1}=\{0\}$. So we have $Z=\operatorname{Im} L \oplus Z_{1}$, and

$$
\operatorname{dim} \operatorname{Ker} L=\operatorname{dim} Z_{1}=\text { co } \operatorname{dim} \operatorname{Im} L=1 .
$$

Thus $L$ is a Fredholm operator of index zero. 
Now we define a projector $P$ from $Y$ to $Y$ by setting

$$
P x=x^{\prime}(0) t \text {. }
$$

Then the generalized inverse $K_{P}: \operatorname{Im} L \longrightarrow \operatorname{dom} L \cap \operatorname{Ker} P$ of $L$ can be written by

$$
K_{P} y=\int_{0}^{t} \int_{0}^{s} \int_{0}^{\tau} y(v) d v d \tau d s .
$$

In fact, for $y \in \operatorname{Im} L$, we have

$$
\left(L K_{P}\right) y(t)=\left[\left(K_{P} y\right)(t)\right]^{\prime \prime \prime}=y(t),
$$

and for $x \in \operatorname{dom} L \cap \operatorname{Ker} P$, we know

$$
\left(K_{P} L\right) x(t)=\int_{0}^{t} \int_{0}^{s} \int_{0}^{\tau} x^{\prime \prime \prime}(v) d v d \tau d s=x(t)-x(0)-x^{\prime}(0) t-\frac{1}{2} x^{\prime \prime}(0) t^{2},
$$

in view of $x \in \operatorname{dom} L \cap \operatorname{Ker} P, x(0)=x^{\prime \prime}(0)=0$ and $P x=0$, thus

$$
\left(K_{P} L\right) x(t)=x(t) .
$$

This shows that $K_{P}=\left(\left.L\right|_{\operatorname{dom} L \cap \operatorname{Ker} P}\right)^{-1}$. Also we have

$$
\left\|K_{P} y\right\|_{\infty} \leq \int_{0}^{1} \int_{0}^{1} \int_{0}^{1}|y(v)| d v d \tau d s=\|y\|_{1},
$$

and from $\left(K_{P} y\right)^{\prime}(t)=\int_{0}^{t} \int_{0}^{\tau} y(v) d v d \tau,\left(K_{P} y\right)^{\prime \prime}(t)=\int_{0}^{t} y(v) d v$, we obtain

$$
\begin{gathered}
\left\|\left(K_{P} y\right)^{\prime}\right\|_{\infty} \leq \int_{0}^{1} \int_{0}^{1}|y(v)| d v d \tau=\|y\|_{1}, \\
\left\|\left(K_{P} y\right)^{\prime \prime}\right\|_{\infty} \leq \int_{0}^{1}|y(v)| d v=\|y\|_{1},
\end{gathered}
$$

then $\left\|K_{P} y\right\| \leq\|y\|_{1}$. This completes the proof of Lemma 2.1 .

Lemma 2.2. Let $\Omega_{1}=\{x \in \operatorname{dom} L \backslash \operatorname{Ker} L: L x=\lambda N x$ for some $\lambda \in[0,1]\}$. Then $\Omega_{1}$ is a bounded subset of $Y$.

Proof. Suppose that $x \in \Omega_{1}$ and $L x=\lambda N x$. Thus $\lambda \neq 0$ and $Q N x=0$, so that

$$
\sum_{j=1}^{m-2} \beta_{j} \int_{\eta_{j}}^{1} \int_{0}^{\tau} f\left(v, x(v), x^{\prime}(v), x^{\prime \prime}(v)\right) d v d \tau=0,
$$


namely,

$$
\begin{aligned}
\sum_{j=1}^{m-2} \beta_{j} & {\left[\int_{0}^{\eta_{j}}\left(1-\eta_{j}\right) f\left(v, x(v), x^{\prime}(v), x^{\prime \prime}(v)\right) d v\right.} \\
+ & \left.\int_{\eta_{j}}^{1}(1-v) f\left(v, x(v), x^{\prime}(v), x^{\prime \prime}(v)\right) d v\right]=0 .
\end{aligned}
$$

Thus, by condition (2), there exists $t_{0} \in[0,1]$, such that $\left|x^{\prime}\left(t_{0}\right)\right| \leq M$. In view of

$$
x^{\prime}(0)=x^{\prime}\left(t_{0}\right)-\int_{0}^{t_{0}} x^{\prime \prime}(t) d t, \quad x^{\prime \prime}(t)=x^{\prime \prime}(0)-\int_{0}^{t} x^{\prime \prime \prime}(t) d t
$$

then, we have

(2.8) $\left|x^{\prime}(0)\right| \leq M+\int_{0}^{1} \int_{0}^{1}\left|x^{\prime \prime \prime}\right| d t=M+\left\|x^{\prime \prime \prime}\right\|_{1}=M+\|L x\|_{1} \leq M+\|N x\|_{1}$.

Again for $x \in \Omega_{1}, x \in \operatorname{dom} L \backslash \operatorname{Ker} L$, then $(I-P) x \in \operatorname{dom} L \cap \operatorname{Ker} P, L P x=0$, thus from Lemma 2.1, we know

$$
\|(I-P) x\|=\left\|K_{P} L(I-P) x\right\| \leq\|L(I-P) x\|_{1}=\|L x\|_{1} \leq\|N x\|_{1} .
$$

From (2.8) and (2.9), we have

$$
\|x\| \leq\|P x\|+\|(I-P) x\|=\left|x^{\prime}(0)\right|+\|(I-P) x\| \leq 2\|N x\|_{1}+M .
$$

From (2.1) and (2.10), we obtain

$$
\|x\| \leq 2\left[\|a\|_{1}\|x\|_{\infty}+\|b\|_{1}\left\|x^{\prime}\right\|_{\infty}+\|c\|_{1}\left\|x^{\prime \prime}\right\|_{\infty}+\|r\|_{1}+\frac{M}{2}\right] .
$$

Thus, from $\|x\|_{\infty} \leq\|x\|$ and (2.11), we have

$$
\|x\|_{\infty} \leq \frac{2}{1-2\|a\|_{1}}\left[\|b\|_{1}\left\|x^{\prime}\right\|_{\infty}+\|c\|_{1}\left\|x^{\prime \prime}\right\|_{\infty}+\|r\|_{1}+\frac{M}{2}\right] .
$$

From $\left\|x^{\prime}\right\|_{\infty} \leq\|x\|$, (2.11) and (2.12), one has

$$
\begin{aligned}
\left\|x^{\prime}\right\|_{\infty} & \leq\|x\| \\
& \leq 2\left[1+\frac{2\|a\|_{1}}{1-2\|a\|_{1}}\right]\left[\|b\|_{1}\left\|x^{\prime}\right\|_{\infty}+\|c\|_{1}\left\|x^{\prime \prime}\right\|_{\infty}+\|r\|_{1}+\frac{M}{2}\right] \\
& =\frac{2}{1-2\|a\|_{1}}\left[\|b\|_{1}\left\|x^{\prime}\right\|_{\infty}+\|c\|_{1}\left\|x^{\prime \prime}\right\|_{\infty}+\|r\|_{1}+\frac{M}{2}\right]
\end{aligned}
$$

i.e., 


$$
\left\|x^{\prime}\right\|_{\infty} \leq \frac{2}{1-2\|a\|_{1}-2\|b\|_{1}}\left[\|c\|_{1}\left\|x^{\prime \prime}\right\|_{\infty}+\|r\|_{1}+\frac{M}{2}\right] .
$$

Again from $\left\|x^{\prime \prime}\right\|_{\infty} \leq\|x\|,(2.11)$, (2.12) and (2.13), we get

$$
\begin{aligned}
\left\|x^{\prime \prime}\right\|_{\infty} \leq\|x\| \leq & {\left[2\|b\|_{1}+\frac{4\|a\|_{1}\|b\|_{1}}{1-2\|a\|_{1}}\right]\left\|x^{\prime}\right\|_{\infty} } \\
+ & {\left[\frac{4\|a\|_{1}}{1-2\|a\|_{1}}+2\right]\left[\|c\|_{1}\left\|x^{\prime \prime}\right\|_{\infty}+\|r\|_{1}+\frac{M}{2}\right] } \\
\leq & {\left[\frac{4\|b\|_{1}}{\left(1-2\|a\|_{1}-2\|b\|_{1}\right)\left(1-2\|a\|_{1}\right)}+\frac{2}{1-2\|a\|_{1}}\right] } \\
& \cdot\left[\|c\|_{1}\left\|x^{\prime \prime}\right\|_{\infty}+\|r\|_{1}+\frac{M}{2}\right] \\
= & \frac{2}{1-2\|a\|_{1}-2\|b\|_{1}}\left[\|c\|_{1}\left\|x^{\prime \prime}\right\|_{\infty}+\|r\|_{1}+\frac{M}{2}\right],
\end{aligned}
$$

i.e.,

$$
\left\|x^{\prime \prime}\right\|_{\infty} \leq \frac{2 C_{1}}{1-2\|a\|_{1}-2\|b\|_{1}-2\|c\|_{1}}
$$

where $C_{1}=\|r\|_{1}+\frac{M}{2}$. From (2.14), there exist $M_{1}>0$, such that

$$
\left\|x^{\prime \prime}\right\|_{\infty} \leq M_{1}
$$

thus from (2.15) and (2.13), there exist $M_{2}>0$, such that

$$
\left\|x^{\prime}\right\|_{\infty} \leq M_{2}
$$

therefore from (2.16) and (2.12), there exist $M_{3}>0$, such that

$$
\|x\|_{\infty} \leq M_{3}
$$

Hence

$$
\|x\|=\max \left\{\|x\|_{\infty},\left\|x^{\prime}\right\|_{\infty},\left\|x^{\prime \prime}\right\|_{\infty}\right\} \leq \max \left\{M_{1}, M_{2}, M_{3}\right\} .
$$

Again from (2.1), (2.15), (2.16) and (2.17), we have

$$
\left\|x^{\prime \prime \prime}\right\|_{1}=\|L x\|_{1} \leq\|N x\|_{1} \leq\|a\|_{1} M_{3}+\|b\|_{1}\left\|M_{2}+\right\| c\left\|_{1} M_{1}+\right\| r \|_{1} .
$$

We show that $\Omega_{1}$ is bounded.

Lemma 2.3. The set $\Omega_{2}=\{x \in \operatorname{Ker} L: N x \in \operatorname{Im} L\}$ is bounded. 
Proof. Let $x \in \Omega_{2}$, then $x \in \operatorname{Ker} L=\{x \in \operatorname{dom} L: x=c t, c \in R, t \in[0,1]\}$, and $Q N x=0$, therefore

$$
\sum_{j=1}^{m-2} \beta_{j} \int_{\eta_{j}}^{1} \int_{0}^{\tau} f(v, c v, c, 0) d v d \tau=0
$$

that is

$$
\sum_{j=1}^{m-2} \beta_{j}\left[\int_{0}^{\eta_{j}}\left(1-\eta_{j}\right) f(v, c v, c, 0) d v+\int_{\eta_{j}}^{1}(1-v) f(v, c v, c, 0) d v\right]=0 .
$$

From condition (2), $\|x\|_{\infty}=|c| \leq M$, so $\|x\|=|c| \leq M$, thus $\Omega_{2}$ is bounded.

Lemma 2.3. If the first part of Condition (3) of Theorem 2.2 holds, that is, there exists $M^{*}>0$, such that

$$
c \cdot \frac{2}{1-\sum_{j=1}^{m-2} \beta_{j} \eta_{j}^{2}} \sum_{j=1}^{m-2} \beta_{j} \int_{\eta_{j}}^{1} \int_{0}^{\tau} f(v, c v, c, 0) d v d \tau<0
$$

for all $|c|>M^{*}$. Let

$$
\Omega_{3}=\{x \in \operatorname{Ker} L:-\lambda x+(1-\lambda) J Q N x=0, \lambda \in[0,1]\},
$$

where $J: \operatorname{Im} Q \longrightarrow \operatorname{Ker} L$ is the linear isomorphism given by $J(c)=c t, \forall c \in R$, $t \in[0,1]$. Then $\Omega_{3}$ is bounded.

Proof. Suppose that $x=c_{0} t \in \Omega_{3}$, then we obtain

$$
\lambda c_{0} t=(1-\lambda) \cdot \frac{2 t}{1-\sum_{j=1}^{m-2} \beta_{j} \eta_{j}^{2}} \sum_{j=1}^{m-2} \beta_{j} \int_{\eta_{j}}^{1} \int_{0}^{\tau} f\left(v, c_{0} v, c_{0}, 0\right) d v d \tau, 0 \leq t \leq 1
$$

or equivalently

$$
\lambda c_{0}=(1-\lambda) \cdot \frac{2}{1-\sum_{j=1}^{m-2} \beta_{j} \eta_{j}^{2}} \sum_{j=1}^{m-2} \beta_{j} \int_{\eta_{j}}^{1} \int_{0}^{\tau} f\left(v, c_{0} v, c_{0}, 0\right) d v d \tau
$$


If $\lambda=1$, then $c_{0}=0$. Otherwise, if $\left|c_{0}\right|>M^{*}$, in view of (2.18), one has

$$
\lambda c_{0}^{2}=c_{0} \cdot(1-\lambda) \cdot \frac{2}{1-\sum_{j=1}^{m-2} \beta_{j} \eta_{j}^{2}} \sum_{j=1}^{m-2} \beta_{j} \int_{\eta_{j}}^{1} \int_{0}^{\tau} f\left(v, c_{0} v, c_{0}, 0\right) d v d \tau<0
$$

which contradicts $\lambda c_{0}^{2} \geq 0$. Then $|x|=\left|c_{0} t\right| \leq\left|c_{0}\right| \leq M^{*}$, we obtain $\|x\| \leq M^{*}$, therefore $\Omega_{3} \subset\left\{x \in \operatorname{Ker} L:\|x\| \leq M^{*}\right\}$ is bounded.

The proof of Theorem 2.2 is now an easy consequence of the above lemmas and Theorem 2.1.

Proof of Theorem 2.2. Let $\Omega=\{x \in Y:\|x\|<d\}$ such that $\bigcup_{i=1}^{3} \bar{\Omega}_{i} \subset \Omega$. By the Ascoli-Arzela theorem, it can be shown that $K_{P}(I-Q) N: \bar{\Omega} \longrightarrow Y$ is compact, thus $N$ is $L$-compact on $\bar{\Omega}$. Then by the above Lemmas, we have

(i) $L x \neq \lambda N x$ for every $(x, \lambda) \in[(\operatorname{dom} L \backslash \operatorname{Ker} L) \cap \partial \Omega] \times(0,1)$.

(ii) $N x \notin \operatorname{Im} L$ for every $x \in \operatorname{Ker} L \cap \partial \Omega$.

(iii) Let $H(x, \lambda)=-\lambda x+(1-\lambda) J Q N x$, with $J$ as in Lemma 2.4. We know $H(x, \lambda) \neq 0$, for $x \in \operatorname{Ker} L \cap \partial \Omega$. Thus, by the homotopy property of degree, we get

$$
\begin{aligned}
\operatorname{deg}\left(\left.J Q N\right|_{\text {Ker } L}, \Omega \cap \operatorname{Ker} L, 0\right) & =\operatorname{deg}(H(\cdot, 0), \Omega \cap \operatorname{Ker} L, 0) \\
& =\operatorname{deg}(H(\cdot, 1), \Omega \cap \operatorname{Ker} L, 0) \\
& =\operatorname{deg}(-I, \Omega \cap \operatorname{Ker} L, 0) .
\end{aligned}
$$

According to definition of degree on a space which is isomorphic to $R^{n}, n<\infty$, and

$$
\Omega \bigcap \operatorname{Ker} L=\{c t:|c|<d\}
$$

We have

$$
\begin{aligned}
\operatorname{deg}(-I, \Omega \cap \operatorname{Ker} L, 0) & =\operatorname{deg}\left(-J^{-1} I J, J^{-1}(\Omega \cap \operatorname{Ker} L), J^{-1}\{0\}\right) \\
& =\operatorname{deg}(-I,(-d, d), 0)=-1 \neq 0
\end{aligned}
$$

and then

$$
\operatorname{deg}\left(\left.J Q N\right|_{\operatorname{Ker} L}, \Omega \cap \operatorname{Ker} L, 0\right) \neq 0 .
$$

Then by Theorem 2.1, $L x=N x$ has at least one solution in $\operatorname{dom} L \cap \bar{\Omega}$, so that the BVP (1.1), (1.2) has at least one solution in $C^{2}[0,1]$. The proof is completed. 
Remark 2.1. If the second part of Condition(3) of Theorem 2.2 holds, that is,

$$
c \cdot \frac{2}{1-\sum_{j=1}^{m-2} \beta_{j} \eta_{j}^{2}} \sum_{j=1}^{m-2} \beta_{j} \int_{\eta_{j}}^{1} \int_{0}^{\tau} f(v, c v, c, 0) d v d \tau>0,
$$

for all $|c|>M^{*}$, then in Lemma 2.4, we take

$$
\Omega_{3}=\{x \in \operatorname{Ker} L: \lambda x+(1-\lambda) J Q N x=0, \lambda \in[0,1]\},
$$

and exactly as there, we can prove that $\Omega_{3}$ is bounded. Then in the proof of Theorem 2.2 , we have

$$
\operatorname{deg}\left(\left.J Q N\right|_{\operatorname{Ker} L}, \Omega \cap \operatorname{Ker} L, 0\right)=\operatorname{deg}(I, \Omega \cap \operatorname{Ker} L, 0)=1,
$$

since $0 \in \Omega \cap \operatorname{Ker} L$. The remainder of the proof is the same.

By using the same method as in the proof of Theorem 2.2 and Lemmas 2.1-2.4, we can show Lemma 2.5 and Theorem 2.3, when BVP (1.1), (1.2) satisfies the case (ii).

Lemma 2.5. If $\alpha=1, \sum_{j=1}^{m-2} \beta_{j}=1$, then $L: \operatorname{dom} L \subset Y \longrightarrow Z$ is a Fredholm operator of index zero. Furthermore, the linear continuous projector operator $Q: Z \longrightarrow Z$ can be defined by

$$
Q y=\frac{2}{1-\sum_{j=1}^{m-2} \beta_{j} \eta_{j}^{2}} \sum_{j=1}^{m-2} \beta_{j} \int_{\eta_{j}}^{1} \int_{0}^{\tau} y(v) d v d \tau,
$$

and the linear operator $K_{P}: \operatorname{ImL} \longrightarrow \operatorname{dom} L \cap \operatorname{KerP}$ can be written by

$$
K_{P} y=-\frac{t^{2}}{\xi^{2}} \int_{0}^{\xi} \int_{0}^{s} \int_{0}^{\tau} y(v) d v d \tau d s+\int_{0}^{t} \int_{0}^{s} \int_{0}^{\tau} y(v) d v d \tau d s .
$$

Furthermore

$$
\left\|K_{P}\right\| \leq \Delta_{1}\|y\|_{1}, \text { for all } y \in \operatorname{ImL},
$$

here $\Delta_{1}=\frac{2}{\xi}+1$.

Notice that the $\operatorname{Ker} L=\{x \in \operatorname{dom} L: x=d, d \in R\}, \operatorname{Im} L=\{y \in Z:$ $\left.\sum_{j=1}^{m-2} \beta_{j} \int_{\eta_{j}}^{1} \int_{0}^{\tau} y(v) d v d \tau=0\right\}$.

Theorem 2.3. Let $f:[0,1] \times R^{3} \longrightarrow R$ be a continuous function, assume that

(1) The condition (1) in Theorem 2.2 is satisfied. 
(2) There exists a constant $M>0$, such that for $x \in \operatorname{dom} L$, if $|x(t)|>M$, for all $t \in[0,1]$, then

$$
\begin{aligned}
\sum_{j=1}^{m-2} \beta_{j} & {\left[\int_{0}^{\eta_{j}}\left(1-\eta_{j}\right) f\left(v, x(v), x^{\prime}(v), x^{\prime \prime}(v)\right) d v\right.} \\
+ & \left.\int_{\eta_{j}}^{1}(1-v) f\left(v, x(v), x^{\prime}(v), x^{\prime \prime}(v)\right) d v\right] \neq 0
\end{aligned}
$$

(3) There exists a constant $M^{*}>0$, such that either

$$
d \cdot \sum_{j=1}^{m-2} \beta_{j} \int_{\eta_{j}}^{1} \int_{0}^{\tau} f(v, d, 0,0) d v d \tau<0, \text { for all }|d|>M^{*}
$$

or else

$$
d \cdot \sum_{j=1}^{m-2} \beta_{j} \int_{\eta_{j}}^{1} \int_{0}^{\tau} f(v, d, 0,0) d v d \tau>0, \text { for all }|d|>M^{*} .
$$

Then BVP (1.1), (1.2) with $\alpha=1, \sum_{j=1}^{m-2} \beta_{j}=1$, has at least one solution in $C^{2}[0,1]$ provided that

$$
\|a\|_{1}+\|b\|_{1}+\|c\|_{1}<\frac{1}{\Delta_{2}}
$$

where $\Delta_{2}=\Delta_{1}+1, \Delta_{1}$ as in Lemma 2.5 .

Proof. Let

$$
\Omega_{1}=\{x \in \operatorname{dom} L \backslash \operatorname{Ker} L: L x=\lambda N x \text { for some } \lambda \in[0,1]\} .
$$

Then for $x \in \Omega_{1}, L x=\lambda N x$, thus $\lambda \neq 0, N x \in \operatorname{Im} L=\operatorname{Ker} Q$, hence

$$
\sum_{j=1}^{m-2} \beta_{j} \int_{\eta_{j}}^{1} \int_{0}^{\tau} f\left(v, x(v), x^{\prime}(v), x^{\prime \prime}(v)\right) d v d \tau=0,
$$

that is

$$
\begin{aligned}
\sum_{j=1}^{m-2} \beta_{j} & {\left[\int_{0}^{\eta_{j}}\left(1-\eta_{j}\right) f\left(v, x(v), x^{\prime}(v), x^{\prime \prime}(v)\right) d v\right.} \\
+ & \left.\int_{\eta_{j}}^{1}(1-v) f\left(v, x(v), x^{\prime}(v), x^{\prime \prime}(v)\right) d v\right]=0 .
\end{aligned}
$$

Thus, from condition (2), there exists $t_{0} \in[0,1]$, such that $\left|x\left(t_{0}\right)\right|<M$, in view of $x(0)=x\left(t_{0}\right)-\int_{0}^{t_{0}} x^{\prime}(t) d t$, we obtain

$$
|x(0)| \leq M+\left\|x^{\prime}\right\|_{\infty} .
$$


From $x(0)=\alpha x(\xi)=x(\xi)$, there exists $t_{1} \in(0, \xi)$, such that $x^{\prime}\left(t_{1}\right)=0$, thus from $x^{\prime}(t)=x^{\prime}\left(t_{1}\right)+\int_{t_{1}}^{t} x^{\prime \prime}(t) d t$, one has

$$
\left\|x^{\prime}\right\|_{\infty} \leq\left\|x^{\prime \prime}\right\|_{1} \text {. }
$$

Again from $x^{\prime \prime}(0)=0$, thus from $x^{\prime \prime}(t)=x^{\prime \prime}(0)+\int_{t_{2}}^{t} x^{\prime \prime \prime}(t) d t$, we obtain

$$
\left\|x^{\prime \prime}\right\|_{\infty} \leq\left\|x^{\prime \prime \prime}\right\|_{1} \text {. }
$$

We let $P x=x(0)$, hence from (2.20), (2.21) and (2.22), we have

$$
\begin{aligned}
\|P x\|=|x(0)| & \leq M+\left\|x^{\prime}\right\|_{\infty} \leq M+\left\|x^{\prime \prime}\right\|_{1} \leq M+\left\|x^{\prime \prime}\right\|_{\infty} \\
& \leq M+\left\|x^{\prime \prime \prime}\right\|_{1}=M+\|L x\|_{1} \leq M+\|N x\|_{1},
\end{aligned}
$$

thus, by using the same method as in the proof of Lemma 2.2, we can prove that $\Omega_{1}$ is bounded too. Similar to the other proof of Lemmas 2.3-2.4 and Theorem 2.2, we can verify Theorem 2.3.

\section{EXAMPLE}

Example. Consider the following boundary value problem:

$$
\begin{aligned}
& x^{\prime \prime \prime}=t^{2}+4+\sin (x)^{2}+\frac{1}{5}(t+1) x^{\prime}+\cos \left(x^{\prime \prime}\right)^{3}, \quad t \in(0,1), \\
& x^{\prime}(0)=0, \quad x^{\prime \prime}(0)=0, \quad x(1)=\frac{1}{4} x\left(\frac{1}{4}\right)+\frac{1}{6} x\left(\frac{1}{3}\right)+\frac{7}{12} x\left(\frac{1}{2}\right),
\end{aligned}
$$

where

$$
f(t, x, y, z)=t^{2}+4+\sin (x)^{2}+\frac{1}{5}(t+1) y+\cos z^{3}, t \in(0,1),
$$

$\alpha=0, \beta_{1}=\frac{1}{4}, \beta_{2}=\frac{1}{6}, \beta_{3}=\frac{7}{12}, \eta_{1}=\frac{1}{4}, \eta_{2}=\frac{1}{3}, \eta_{3}=\frac{1}{2}$, then $\beta_{1}+\beta_{2}+\beta_{3}=1$, $\beta_{1} \eta_{1}+\beta_{2} \eta_{2}+\beta_{3} \eta_{3}=\frac{59}{144}<1$, we can choose $a(t)=c(t)=0, b(t)=\frac{2}{5}$, $r(t)=7$, for $t \in[0,1]$, thus

$$
\begin{gathered}
|f(t, x, y, z)| \leq \frac{2}{5}|y|+7, \\
\|a\|_{1}+\|b\|_{1}+\|c\|_{1}=\frac{2}{5}<\frac{1}{2} .
\end{gathered}
$$

Since $f$ has the same sign as $x^{\prime}(t)$ when $\left|x^{\prime}(t)\right|>35$, we may choose $M=M^{*}=$ 35 , and then the conditions (1) - (3) of Theorem 2.2 are satisfied. Theorem 2.2 implies that the BVP (3.1)-(3.2) has at least one solution $x \in C^{2}[0,1]$. 


\section{ACKNOWLEDGMENT}

The authors wish to express their thanks to the referee for his or her very valuable suggestions and corrections.

\section{REFERENCES}

1. W. Feng, J. R. L. Webb, Solvability of $m$-point boundary value problems with nonlinear growth, J. Math. Anal. Appl. 212 (1997), 467-480.

2. B. Prezeradzki, and R. Stańczy, Solvability of a multi-point boundary value problem at resonance, J. Math. Anal. Appl. 264 (2001), 253-261.

3. R. Y. Ma, Multiplicity results for a third order value problem at resonance, Nonlinear Anal. Theory, Math. Appl. 32 (1998), 493-499.

4. R. K. Nagle, and K. L. Pothoven, On a third-order nonlinear boundary value problems at resonance, J. Math. Anal. Appl. 195 (1995), 148-159.

5. C. P. Gupta, On a third-order boundary value problem at resonance, Differential Intergral Equations 2 (1989), 1-12.

6. B. Liu, Solvability of multi-point boundary value problem at resonance (II), Appl. Math. Comput. 136 (2003), 353-377.

7. C. P. Gupta, Solvability of multi-point boundary value problems at resonance, Results Math. 28 (1995) 270-276.

8. J. Mawhin, Topological degree methods in nonlinear boundary value problems, in: NSFCBMS Regional Conference series in Mathematics, American Mathematical Society, providence, RI, 1979.

9. E. Rovderová, Third-order boundary value problem with nonlinear boundary conditions, Nonlinear Anal. Theory, Meth. Appl. 25 (1995), 473-485.

10. Z. Du, W. Ge, and X. Lin, Existence of solution a class of third order nonlinear boundary value problems, J. Math. Anal. Appl. 294 (2004), 104-112.

11. C.P. Gupta, A second order $m$-point boundary value problem at resonance, Nonlinear Anal. Theory, Meth. Appl. 24 (1995), 1483-1489.

12. W. Feng, and J. R. L. Webb, Solvability of three-point boundary value problems at resonance, Nonlinear Anal. Theory, Meth. Appl. 30 (1997), 3227-3238.

Zengji Du, Guolan Cai and Weigao Ge

Department of Mathematics,

Beijing Institute of Technology,

Beijing 100081,

People's Republic of China

E-mail: duzengji@163.com 